\title{
A LITERATURA BRASILEIRA: HORIZONTES CRÍTICOS EM DIÁLOGO HOJE
}

\author{
Zilá Bernd
}

\begin{abstract}
RESUMO: Quand il s'agit de discuter la question de nouveaux horizons pour la Littérature Brésilienne, le présent article vient proposer l'ouverture des perspectives comparatives entre la Littérature brésilienne et les Littératures francophones du Québec et de la Caraïbe. L'importante question de notre appartenance à l'Amérique et l'établissement de dialogues culturels et littéraires interaméricains sont mis en question dans le présent article dont l'objectif est bien celui de présenter le travail réalisé par le groupe de recherche qui élabore un CD-ROM qui rassemble les textes fondateurs du comparativisme littéraire interaméricain. Ce Cd-ROM devra se constituer comme la d'une echerche compartive entre le Brèsil et les Amériques de langue française.
\end{abstract}

PALAVRAS-CHAVE: CD-ROM, literatura comparada, literatura brasileira, literaturas de língua francesa das Américas.

Creio que o convite dos organizadores me foi dirigido no sentido de apresentar, no âmbito deste painel que tratará de novos horizontes para a Literatura Brasileira, a linha de trabalho que venho desenvolvendo no Projeto Integrado de Pesquisa que coordeno há 4 anos e que congrega bolsistas de I. C., de Aperfeiçoamento, mestrandos e doutorandos tendo como ponto de partida a Literatura Brasileira.

Minha pesquisa se situa num entre-lugar entre a literatura brasileira e as literaturas de língua francesa das Américas. Todo professor de literaturas estrangeiras tem complexos de culpa de ser alienado por dedicar-se à cultura do outro. Como dizia Octavio Paz, interessar-se pela cultura do outro é um ideal contraditório pois implica que mudemos sem mudar, que sejamos outros sem deixar de ser nós mesmos. Assim, seguindo a lição de Paz e também a de Machado de Assis, tentei unir as duas pontas do meu interesse literário trazendo para a leitura da Literatura Brasileira aquilo que venho aprendendo no contato com as literaturas francófonas das Américas, sobretudo do Caribe e do Quebec.

Zilá Bernd é professora de Literatura Francesa do Instituto de Letras da UFRGS. 
Quando ouvi falar pela primeira vez no Canadá de duas solidões (two solitudes) para referir à ignorância recíproca dos canadenses de língua francesa em relação aos de língua inglesa e vice-versa, achei um absurdo, pois como explicar que, num mesmo país, cidadãos do leste ignorem a literatura produzida no oeste e vice-versa? Refletindo melhor conclú que as duas solidões também existiam entre o Brasil e o restante da América latina ou do Caribe, entre o Brasil e o Quebec e vice-versa. Só passamos a nos interessar pela literatura latino-americana depois de sua consagração na Europa, ou melhor em Paris que continua sendo a capital cultural da América Latina.

Pierre Nepveu, crítico e poeta quebequense, em recente ensaio intitulado Intérieurs du Nouveau Monde (Interiores do Novo Mundo), publicado em 1998, afirma ter resolvido sair "de sua solidão continental" para suscitar a lancinante questão de nossa vinculação intelectual com a América e não com a Europa. Através de finas análises de escritores das três Américas, Pierre Nepveu nos ensina que viver na América é fazer a experiência de uma privação, de uma falta o que determina a tarefa sempre recomeçada de tentar criar aqui valores do espírito e da cultura. Então ele coloca a pergunta: "Como o Novo Mundo pode se colocar do lado da cultura, do espírito e do pensamento?" Pergunta perturbadora porque nos remete aos adjetivos através dos quais fomos tradicionalmente definidos pelos conquistadores e depois pelos colonizadores: selvagens e bárbaros. Esta definição primordial com que os textos fundadores das Américas nos definiram pela negatividade - "eles não têm armas, não falam, não usam roupas, não possuem escrita" - permanece como uma experiência do vazio a qual nestes 500 anos não temos cessado de querer preencher.

Partimos, pois, do princípio de que há algo em comum aos americanos das três Américas que é esta experiência inicial da falta, esta angústia do vazio que dará origem a muitos romances no Brasil, no Caribe e no Quebec cuja temática se estrutura através da temática da busca, como por exemplo Macunaíma, de Mário de Andrade, e Frontières et tableaux d'Amérique de Noël Audet, romances onde os personagens viajam sem cessar em busca de algo - como a muiraquitã - que é sempre encontrada e novamente perdida.

Estas convergências nos levaram a observar nos contextos latino-americano, antilhano e quebequense quais as soluções encontradas para suprir este luto da origem, qual as estratégias encontradas na caminhada em direção à autonomização da instituição literária e seu lento e progressivo processo de independização dos grandes centros hegemônicos produtores de cultura que tradicionalmente se situaram na Europa.

Para tanto o primeiro passo foi repensar a Literatura Comparada a qual, enquanto disciplina, tendeu desde sempre a um certo "europeucentrismo e também à valorização de certas práticas estéticas limitadas no tempo e no espaço e correspondendo aos momentos fortes das literaturas inglesa, francesa e alemã". O confronto das literaturas com passado colonial como a brasileira e a antilhana, quebequense ou latino-americana, por exemplo, revela-se problemático porque a $\mathrm{Li}$ - 
teratura Comparada em sua origem foi concebida para rastrear "as fontes e as influências" que teriam exercido as literaturas de tradição reconhecida, as literaturas canônicas, sobre as outras com as quais mantiveram contato. Nosso projeto de pesquisa busca estabelecer as bases a partir das quais um comparativismo cultural e literário interamericano pode se construir. Optamos então pela noção de hipertexto. Deixamos de nos preocupar com a noção tradicional de influência em que A transmite algo a B, mas na situação em que B seleciona algo que pode vir de A, B, C, etc, como alegremente propunha o Manifesto Antropófago. Concebemos assim uma análise das relações literárias interamericanas a partir de uma perspectiva não-linear e nãohierarquizada.

Esta perspectiva nos levou a eleger dois caminhos alternativos para a análise literária:

1. utilizar prioritariamente pensadores e críticos latino-americanos e antilhanos como Silviano Santiago, Néstor G. Canclini, Edouard Glissant, Maximilien Laroche, Antonio Candido, Angel Rama, Walter D. Mignolo, Pierre Nepveu, entre outros, cujas teorias emanam da própria realidade americana. Partilhamos as colocações de Walter Mignolo no que tange à importância do lugar de enunciação (locus enunciativo) dessas teorias, salientando, contudo, que este gesto não se confunde com concepções estreitas baseada no politicamente correto, ou na apropriação das vozes que pretende que é preciso ser X para falar de X (mulher, negro, subalterno) ou Y para falar de Y. Consideramos, porém que a pretensão de estabelecer perspectivas comparatistas através do diálogo entre culturas em situação dita periférica, sem tomar a Europa (ou as culturas canônicas) como tertium comparationis, requer que optemos por pensadores que, da própria América, produziram discursos para interpretar a produção cultural emergida em situação colonial ou pós-colonial. Assim pretendemos evitar um tipo de análise onde as obras estudadas são literalmente esmagadas sob o peso de teorias legitimadas pelo centro e que por vezes não dão conta do objeto de análise, pois a maioria dos teóricos europeus conceberam suas teorias para estudar obras consagradas e centradas na tradição européia, desconhecendo inteiramente a heterogeneidade da realidade americana.

2. lançar, sempre que possível, mão de elementos da cultura ou da mitologia précolombiana, para entender os atuais processos culturais, na esteira dos modernistas que elegeram um elemento do ritual tupinambá - a antropofagia - para desenvolver seu manifesto. Com Edouar Glissant aprendemos a valorizar outra característica dos primeiros habitantes da América como o nomadismo, a partir do qual desenvolve a conceito de "pensamento de arquipélago" que ele opõe a "pensamento de sistema" que rege a tradição ocidental. Para os caraíbas e arawakes, que habitavam o mar do Caribe antes da chegada dos conquistadores, as ilhas não significavam isolamento, mas relação, pois navegavam de ilha em ilha, de acordo com os acontecimentos, tendo antes um sentimento de pertença a um arquipélago do que a uma ilha isolada. $\mathrm{O}$ europeu, ao chegar às ilhas, tende a demarcar um território, a enraizar-se, opondo-se à concepção dos índios, pautada pelo nomadismo e pela abertura. Glissant afirma, 
então, que o pensamento de arquipélago estaria nas antípodas de um pensamento de sistema que tende ao absoluto e à imobilidade. Segundo este crítico e romancista antilhano, o pensamento de arquipélago permitiria reconhecer o alcance dos vestígios (trace) das culturas orais que foram desprezadas pelos descobridores que apressaram-se em registrar em seus diários de bordo a inexistência de cultura no Novo Mundo. Maximilien Laroche lança mão de uma figura mitológica do Haiti - o Bizango, ou camaleão voador - que é um ser híbrido, pois tem forma humana durante o dia, adquirindo à noite a capacidade de voar. $\mathrm{O}$ crítico vai, portanto, recolher no imaginário popular um símbolo de mudança e de metamorfose para explicar as literaturas americanas em constante deslocamento em busca de sua expressão. Na base deste procedimento está a aceitação de uma lógica africana muito sutil que admite a aliança dos contrários, representada pelo bizango (camaleão) ao mesmo tempo humano e sobrenatural.

Ir em busca de práticas ancestrais como a antropofagia e o nomadismo e de figuras mitológicas dos autóctones, existentes antes da chegada dos europeus, pode corresponder a uma tentativa dos escritores das Américas de identificarem-se com uma forma de conceber o mundo própria às Américas, onde antropofagia funciona como metáfora da abertura de diálogo intertextual com múltiplas culturas; arquipélago como figuração metonímica de Novo Mundo, por oposição à cultura européia continental, e nomadismo como figura privilegiada de abertura ao Diverso e à relação.

Na verdade o grande fio condutor que perpassa as literaturas das três Américas é a questão da afirmação identitária, por isso, estudar os pólos e as convergências entre autores da literatura brasileira e demais autores americanos nos permite relativizar um certo número de conceitos, perfazendo um caminho de mão dupla. Ao mesmo tempo em que, por exemplo, a representação literária de um "pays incertain" como o Quebec nos instrumentaliza para melhor entender a questão da identidade literária gaúcha e suas aporias, conceitos brasileiros como a Antropofagia podem - e têm sido - aplicados para melhor entender a relação do Quebec com a cultura francesa, como o comprovam os escritos de Walter Moser que depois de estudar a antropofagia a tem aplicado para instigantes análises da literatura canadense. E assim os exemplos poderiam multiplicar-se com a possibilidade de aplicações fertilizadoras de conceitos como o de crioulização, forjado nas Antilhas por Patrick Chamoiseau, que possibilita pensar a identidade de uma forma rizomática, isto é, que contempla o heterogêneo, abrindo-se ao outro na relação.

Este tipo de reflexão nos levou a propor à ANPOLL, a criação de um novo GT, intitulado Relações literárias interamericanas.

Nosso atual projeto de pesquisa CD-ROM-Antologia de textos fundadores para uma teoria da Literatura Comparada Interamericana (1999-2001), inclui a seleção, tradução, comentário e montagem de hipertextos de aproximadamente 70 autores das três Américas, isto é, que escreveram em inglês, português, espanhol e francês para o português. O objetivo é flagrar nestes textos, onde basicamente a consciência de americanidade e de identidade americana emerge, as constantes discursivas que nos 
permitam elaborar um método de análise comparatista para pôr em relação textos das três Américas e seus processos de autonomização e de construção identitária, apontando as bases se de um diálogo interamericano.

Após a sua conclusão, esta formidável amostragem de ensaios escritos nos diferentes pontos das Américas, ao longo de um século, servirá de base para um segundo projeto de pesquisa que investigará as migrações e transferências de determinados conceitos de um pólo a outro do continente americano. $\mathrm{O}$ fenômeno do transculturalismo deverá apontar para a migração de idelogemas que estão na base da definição de processos de construção/desconstrução da americanidade e da americanização. Constata-se que foi recorrente na formação cultural americana o fenômeno da hibridação cultural, gerando, através de justaposições, telescopagens e intersecções, estéticas compósitas. Conclui-se que pode ser de grande utilidade, na prática comparatista, a detecção, nos contextos literários de análise, dos movimentos transculturais, ou seja, de migração e de transferência de determinadas formações discursivas. Fugindo de uma oposição simplesmente binária e linear, o método proposto chama a atenção não apenas para os mecanismos de distanciação em relação às culturas dominantes como para as mesclas de elementos heteróclitos e permite desenhar o mapa do processo de autonomização - descontínuo e inacabado- das literaturas das Américas, retraçando assim a história de seu processo de americanização.

A nossa proposta de leitura dos textos literários americanos para o próximo biênio (2001-2003) aponta para a utilização cada vez mais frequente dos conceitos de americanidade e americanização sinalizando mudanças de formas de identidade nacional homogêneas. Para a manutenção das identidades nacionais homogêneas, de raiz única, recorria-se tanto a processos de censura (não permitir a inclusão de culturas orais e populares, por exemplo), de assimilação (dissolução das diferenças com a permanência apenas da cultura hegemônica) e de exclusão (alijar para a periferia do sistema tudo o que for considerado impuro ou estrangeiro). A identificação cada vez mais freqüente com a América e a emergência da americanidade, como formação identitária que se superpõe às identidades nacionais, são reveladoras de que as noções de pluralidade e diversidade acabaram por vingar. As tentativas de preservar identidades nacionais, voltadas sobre si mesmas e temerosas de "contaminações" vindas da cultura popular ou do exterior, cedem lugar à aceitação da impureza, das imbricações e hibridações culturais. Processos de crioulização intensificam-se nas Américas, trazendo como conseqüência a possibilidade de uma americanidade compartilhada. São fatores de americanização, a inserção cada vez maior de elementos da oralidade na literatura erudita, a emergência de expressões literárias da negritude, a coexistência de vários códigos simbólicos em um mesmo grupo, a interpenetração de vários níveis de linguagem e de diferentes gêneros, a intersecção de diversos sistemas culturais, etc. compondo um quadro identitário poliglota, multiétnico e migrante, como refere Néstor García Canclini em Culturas híbridas; estrategias para entrar y salir d ela modernidad, de 1995. 


\section{BIBLIOGRAFIA}

ANDRĖS, Bernard \& BERND, Zilá., org. L'identitaire et le littéraire dans les Amériques. Québec, Nota Bene, 1999.

AUDET, Noël. Frontières et tableaux du Nouveau Monde. Montréal, Québec/ Amérique, 1992.

BERNABË, J.; CHAMOISEAU, P.; CONFIANT, R. Eloge de la créolité. Paris, Seuil, 1990.

BERND, Zilá, org. CD-ROM Antologia de textos fundadores do comparativismo literário interamericano. Porto Alegre, UFRGS/ABECAN, 2001.

BERND, Zilá, org. Escrituras híbridas, estudos em literatura comparada interamericana. Porto Alegre, Ed. da UFRGS, 1998.

CANCLINI, Nésto García. Culturas hibridas; estrategias para entrar y salir de la modernidad. Mexico, Grijalbo, 1995.

CHAMOISEAU, Patrick. Écrire en pays dominé. Paris, Gallimard, 1997.

GLISSANT, Edouard. Poétique de la relation. Paris, Seuil, 1990.

. Traité du Tout-Monde. Paris, Gallimard, 1997.

GODZICH, Wlad. A la recherche du tertium comparationis. In: PETERSON, M. \& BERND, Z., éds. Confluences littéraires: Brésil/Québec: les bases d'une comparaison. Montréal, Balzac, 1992. p.41-56.

LAROCHE, Maximilien. Bizango, o camaleão voador. In: Bernd, Z., org. Escrituras híbridas. Porto Alegre, Ed. da UFRGS, 1998. p. 29-41. (Traduzido por Z. Bernd)

LÉTOURNEAU, Jocelyn. Passer à l'avenir; histoire, mémoire, identité dans le Québec d'aujourd'hui. Montréal, Boréal, 2000.

MOSER, Walter et alii, éds. Recyclages. Montréal, Balzac, 1996.

NEPVEU, Pierre. Intérieurs du Nouveau Monde. Montréal, Boréal, 1998. 